\title{
FINE ARTS
}

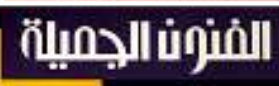

مجلة علمية محكمة

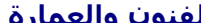

تصدر نصف سنونة

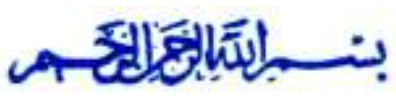

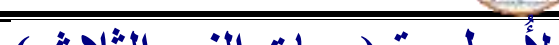

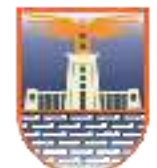

كلبة الفنون الحمبلة الإسيلة

وكيل الكلية للدراسات العليالة

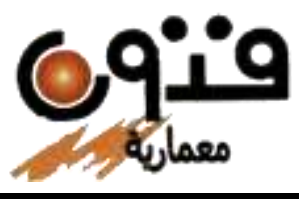

التثاول التصويرى لأسطورة ( ربات النعم الثثلاث )

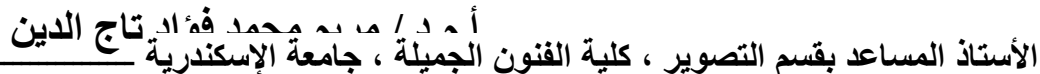

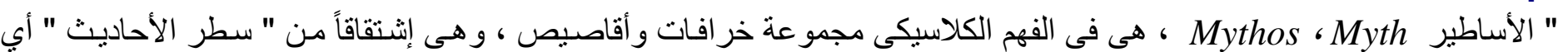

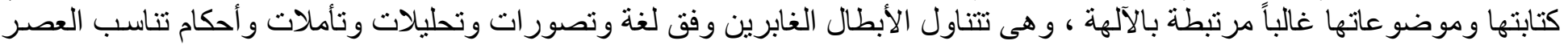

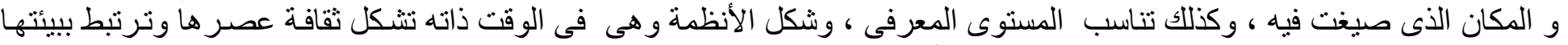

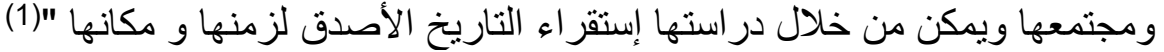

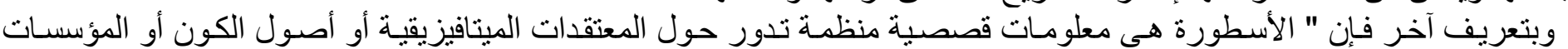

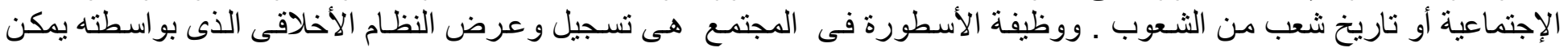

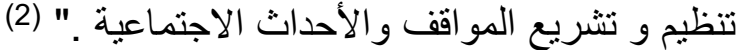

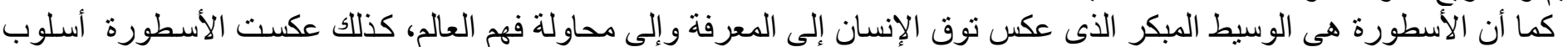

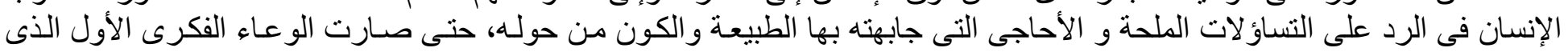

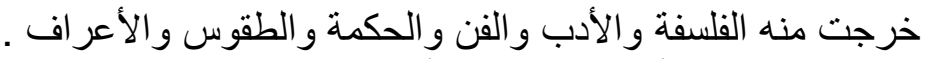

ولقد مرت بالأسطورة آلاف الأعوام ، لم يتوقف إيداعها حتى يومنا هذا ، على الرغم من ظهور التفسير ات العلمية للظواهر الكونية "

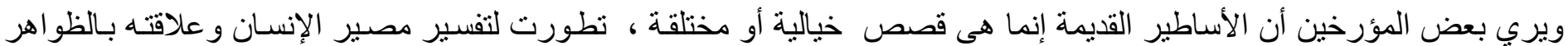

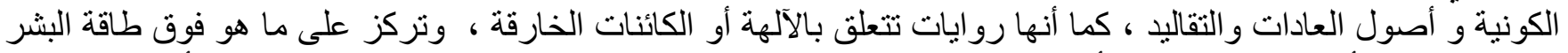

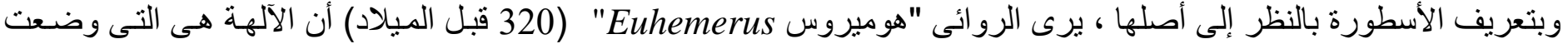

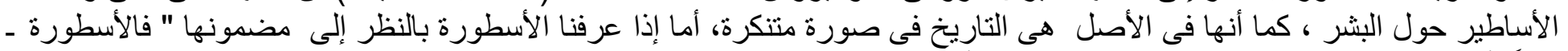

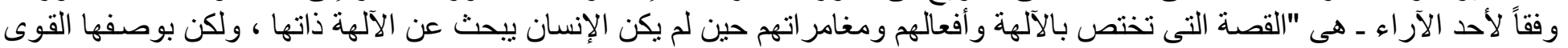


الغيبية التى تسيطر على الظواهر الكونية وتنظمها " كما تبدو فى تعريف آخر على أنها " روايات معينة تتعلق بالآلهة أو الكائنات الخارقة

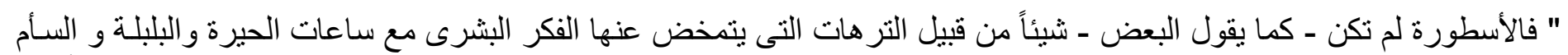

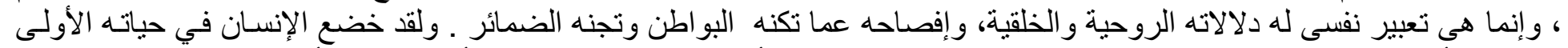

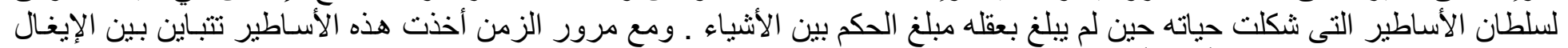

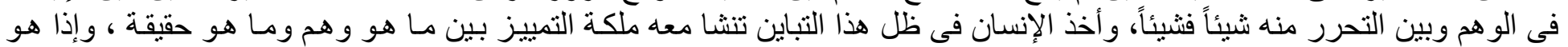

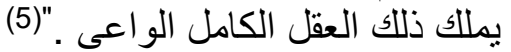

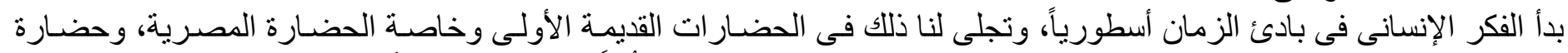

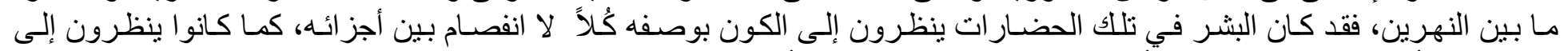

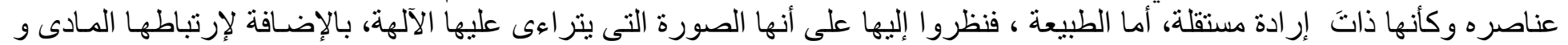
الروحى بالبشرية .

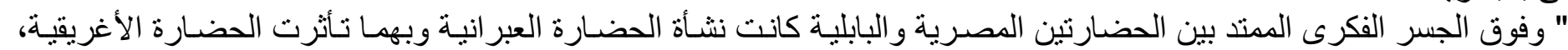

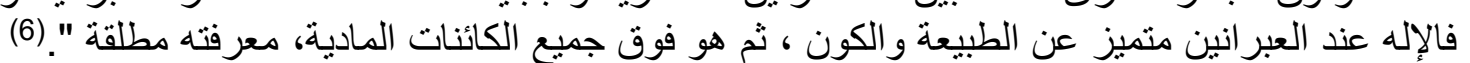

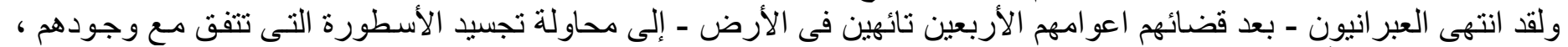

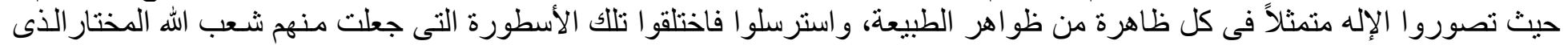

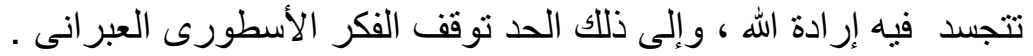

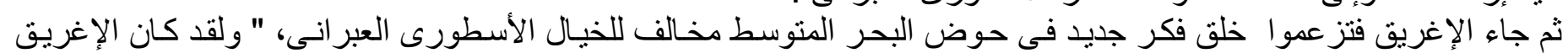

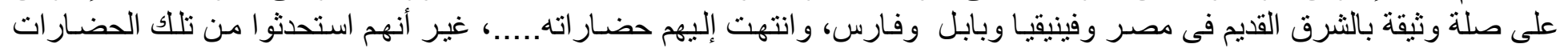

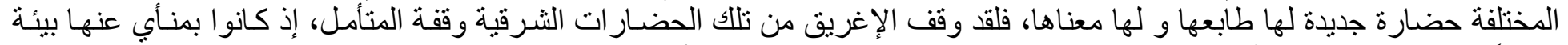

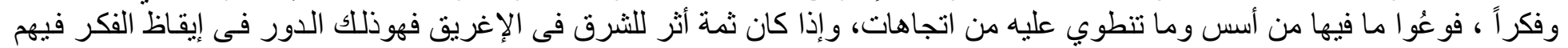

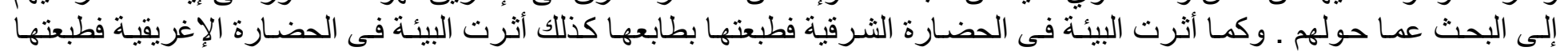

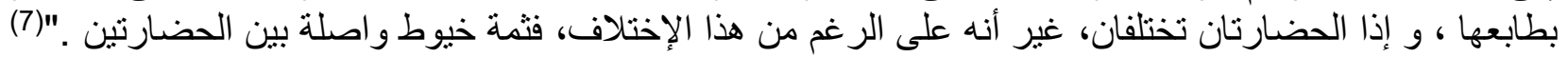

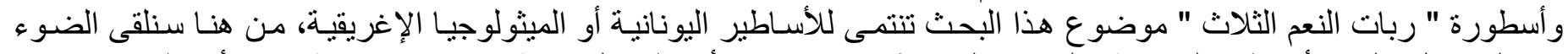

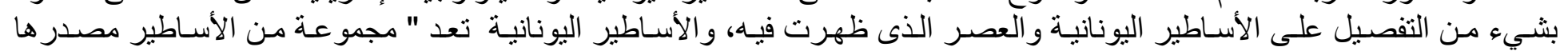




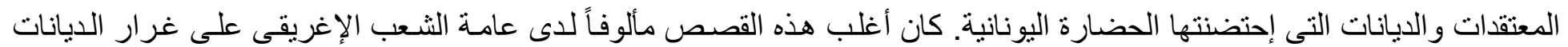

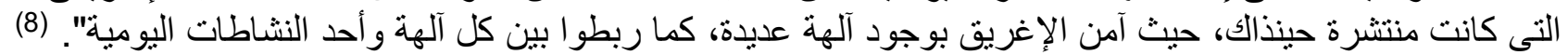

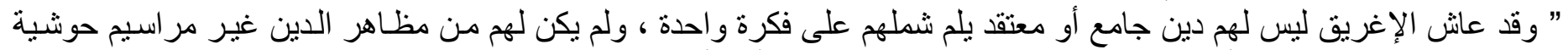

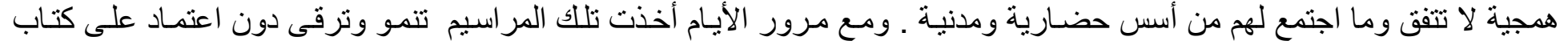

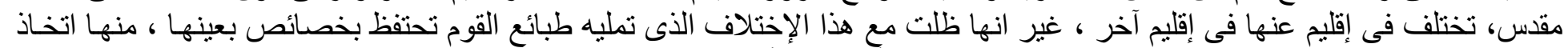

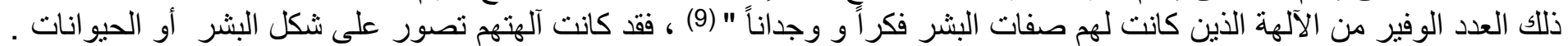

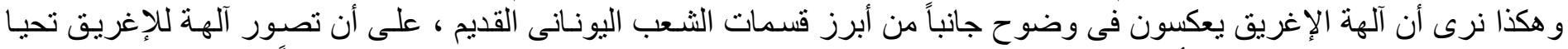

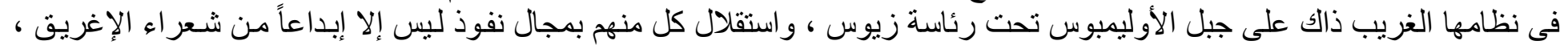

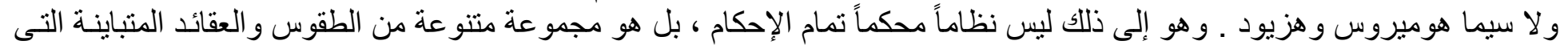

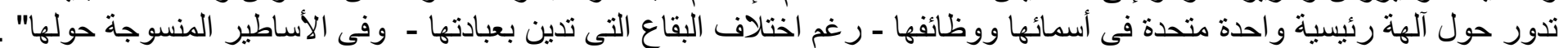

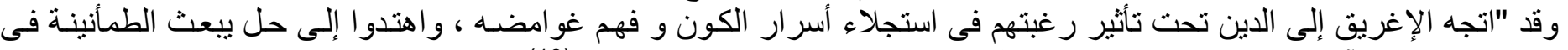

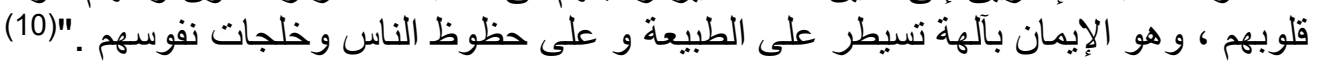

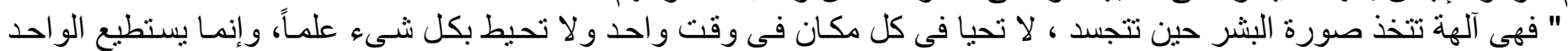

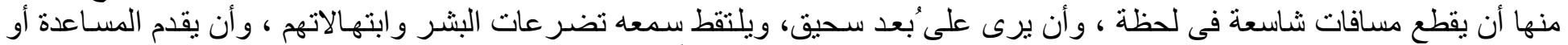

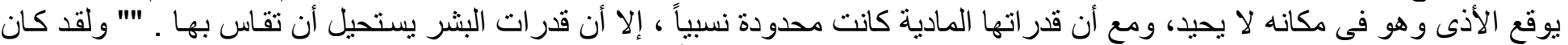

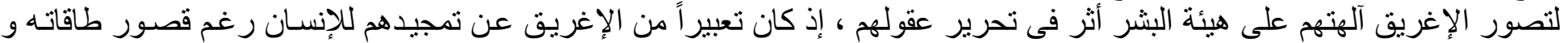

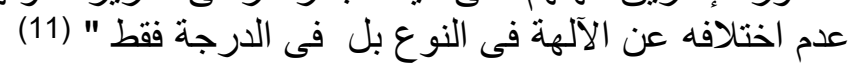

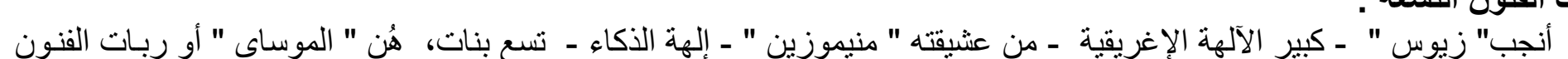

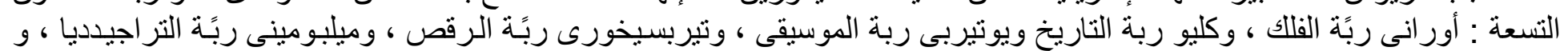

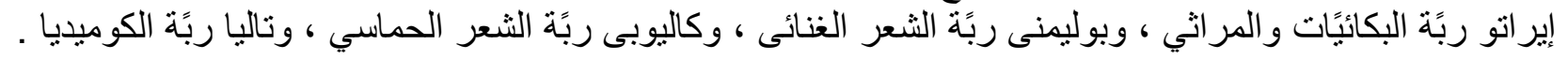




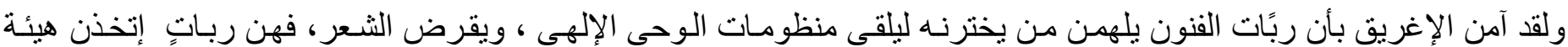

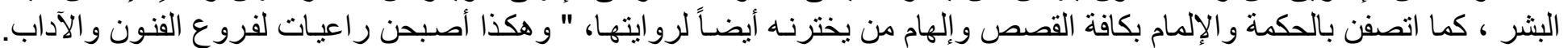

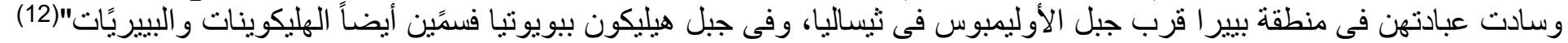
ربات النعم الثلاث

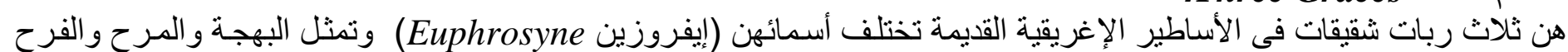

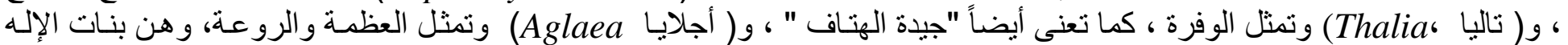

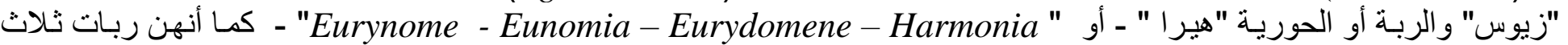

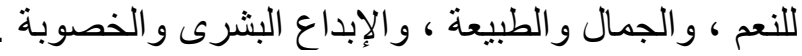

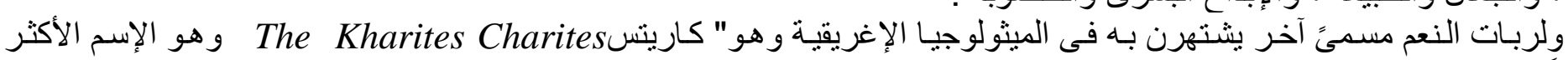

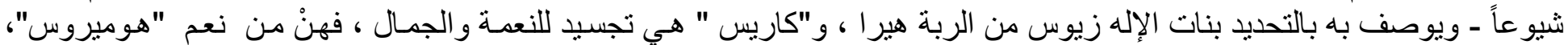

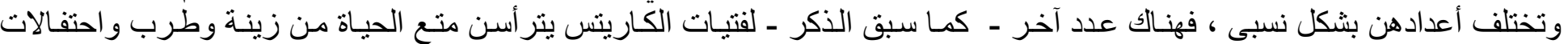

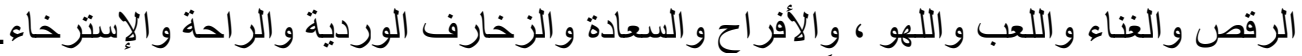

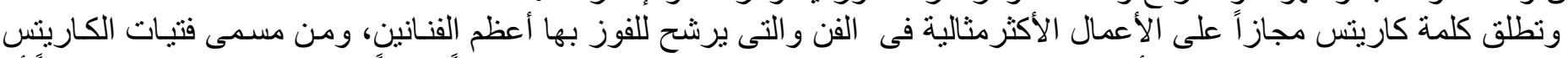

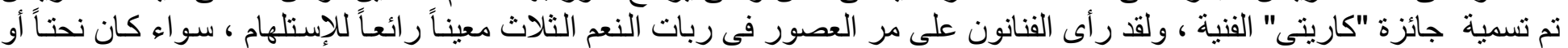

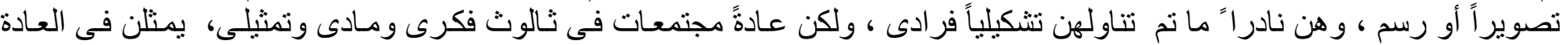

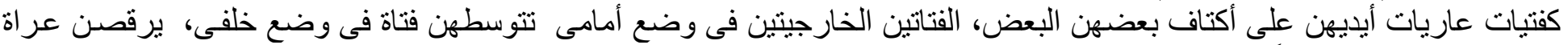

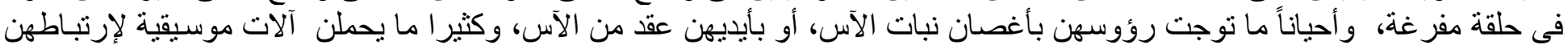

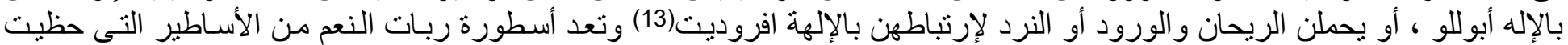

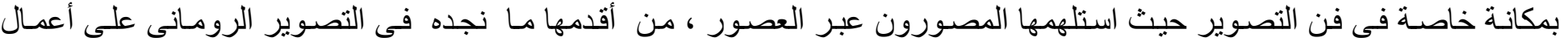

جدارية فى مدينة Pompeii (شكل فن 1.

(108)

يلة ، جامعة الإسكندرية

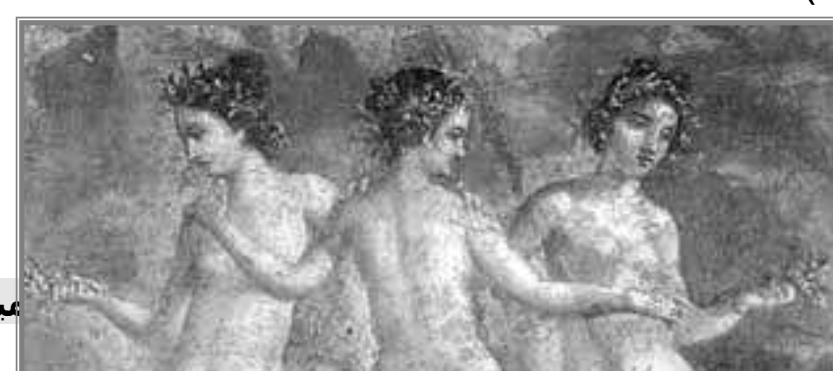

- Fine Arts مجلة الفنون الجميلة 
Roman fresco from Pompeii The Three Graces

Archaeological Museum of Naples ،C1st A.D.

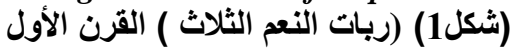

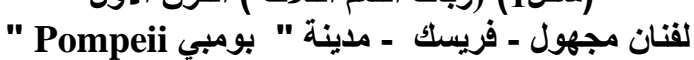

نتناول هنا بعضاً من المصورين الذين قد استكهموا تلك الأسطورة فى أعمالهم الفنية من عصور مختلفة :

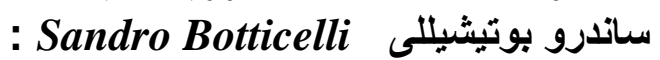

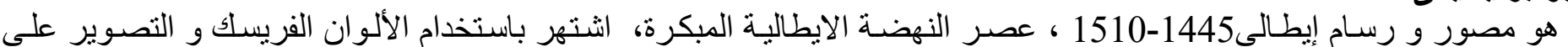

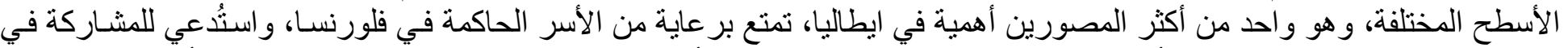

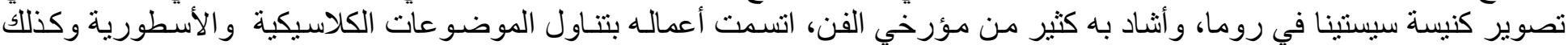

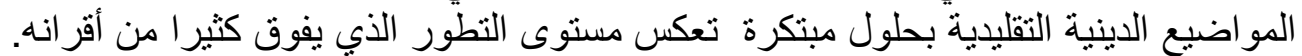

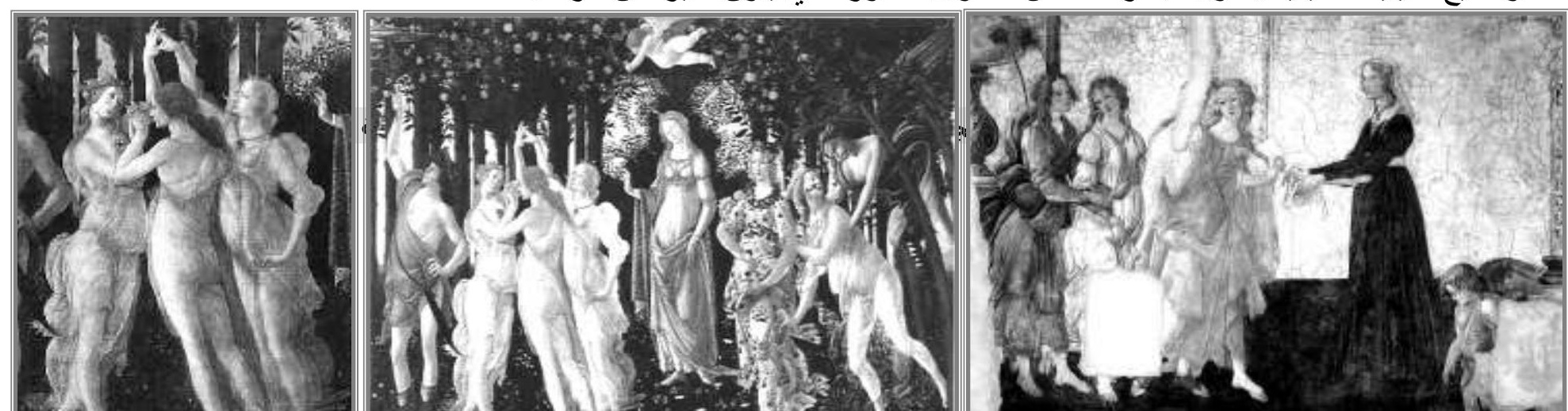


( شكل 4) ساندرو بوتيثيللى ، " الربيع الثبان " Springtime

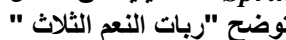

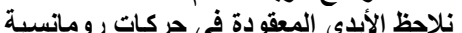

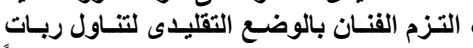

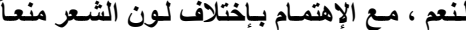

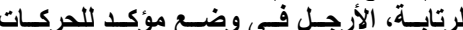

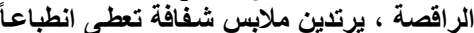

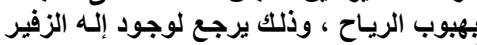

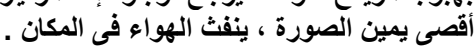

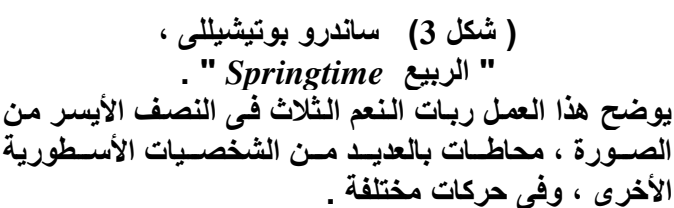

(شكل2) ساندرو بوتيشيللي ، "فينوس وربات النعم الثلاث

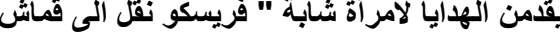
،

تيناول هذا العمل موضوعاً اسطورياً من الأسـاطير الإغريقية،

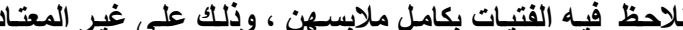
في التناول التشكيلى لربات بكات النعم الثلاث .

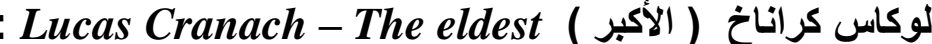

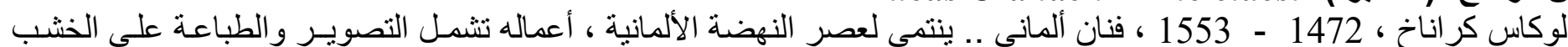

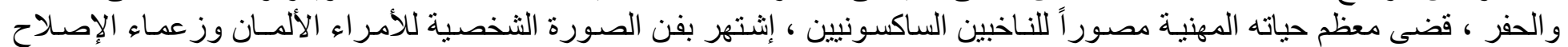

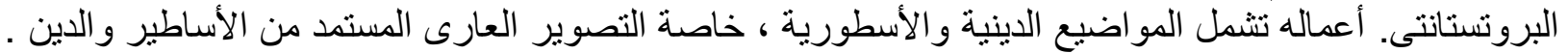

بالاونج هانز Hans ،Baldung Grien

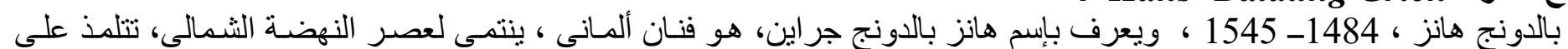

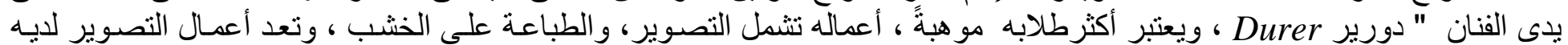

مجلة الفنون الجميلة Fine Arts - فنون معمارية ، مجلة ربع سنوية تصدر عن كلية الفنون الجميلة ، جامعة الإسكندرية (110) 


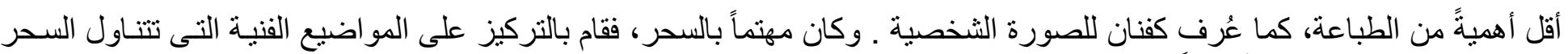

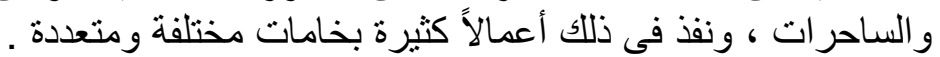

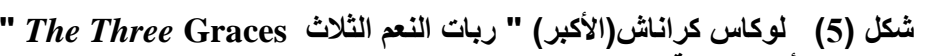

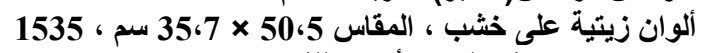

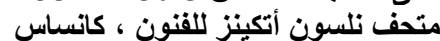

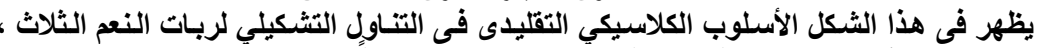

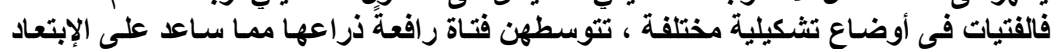

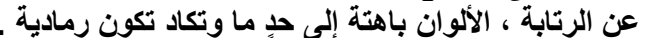

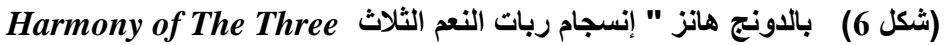
. Graces

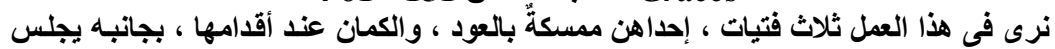

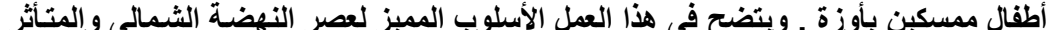

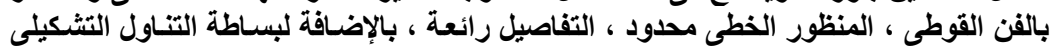

\section{: Rapha}

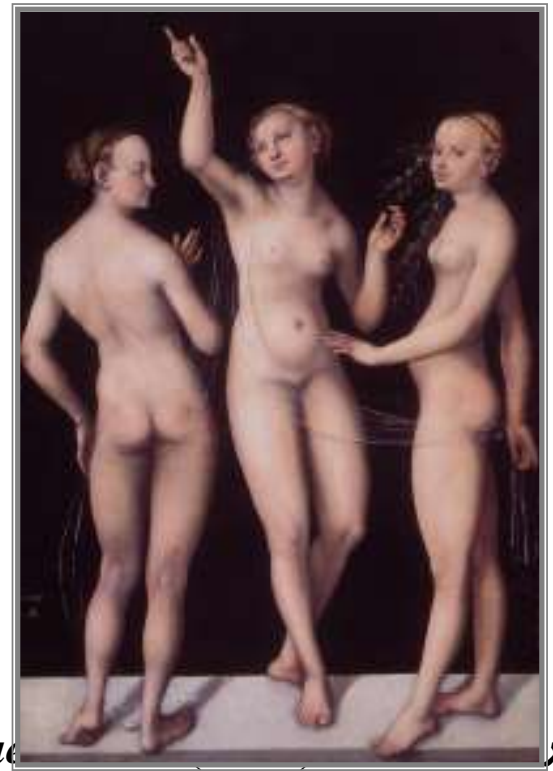

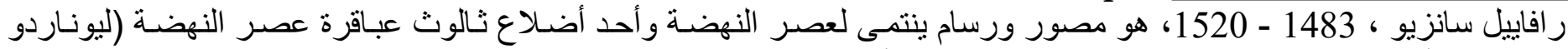

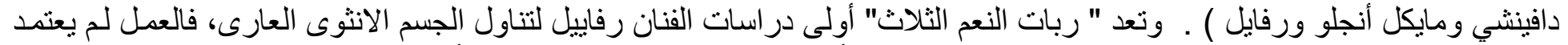

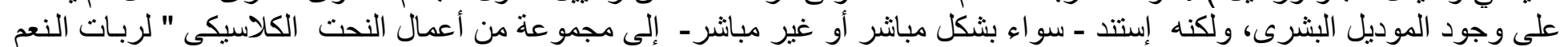

الثلاث " بكاتدر ائية " بيكولوديني البرى ودينى " بمكتبة سيينا .

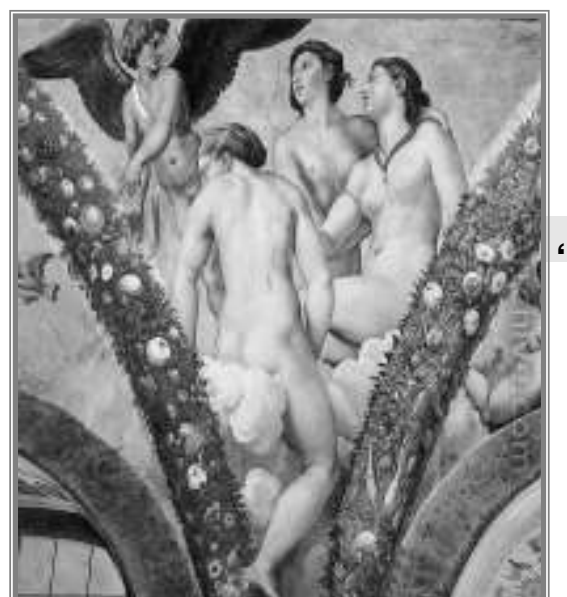

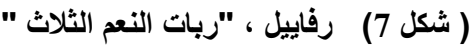

1505 - 1501

ألوان زيتية على لوح17 × 17 17سم

متحف Chantilly،Conde فرنسا

فنون معمارية ، محلة ربع سنوية تصدر عن كلة الفنون الحملة ،

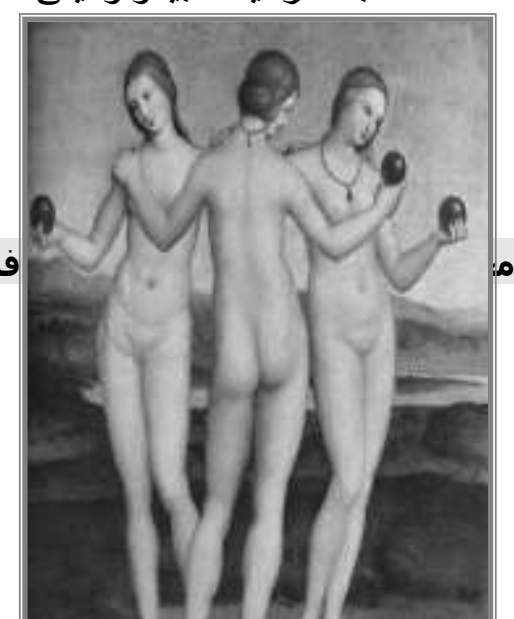


نلاحظ فى هذا العمل اتباع الفنان للثكل التقليدى لوضع الأثخاص ، الفتاتان

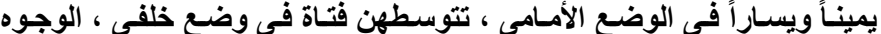

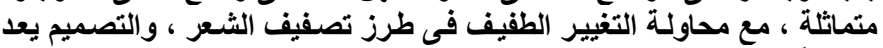
نموذجاً لأثكال التكوين فى عصر ألنهضة التى اعتمدت على فكرة التماثل .

(شكل8) رفاييل " كيوبيا وربات النعم الثلاث 1517 " Cupid and The Three Graces

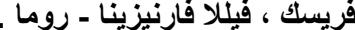

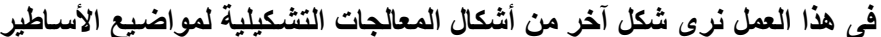

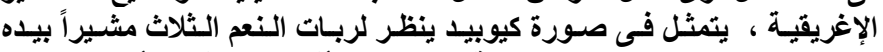

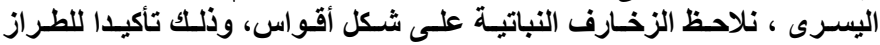

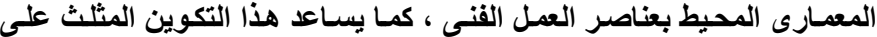

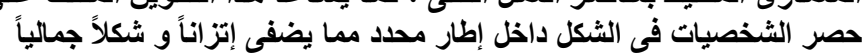

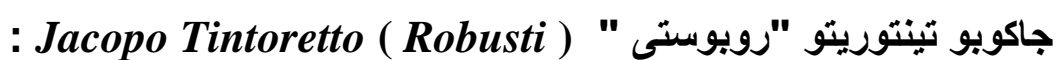

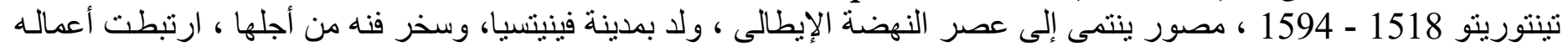

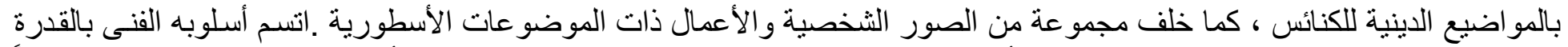

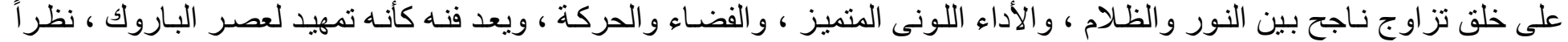

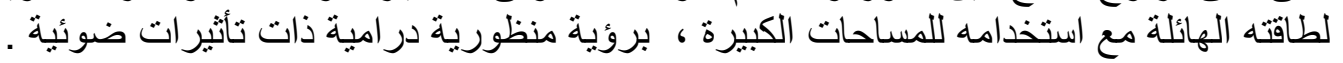

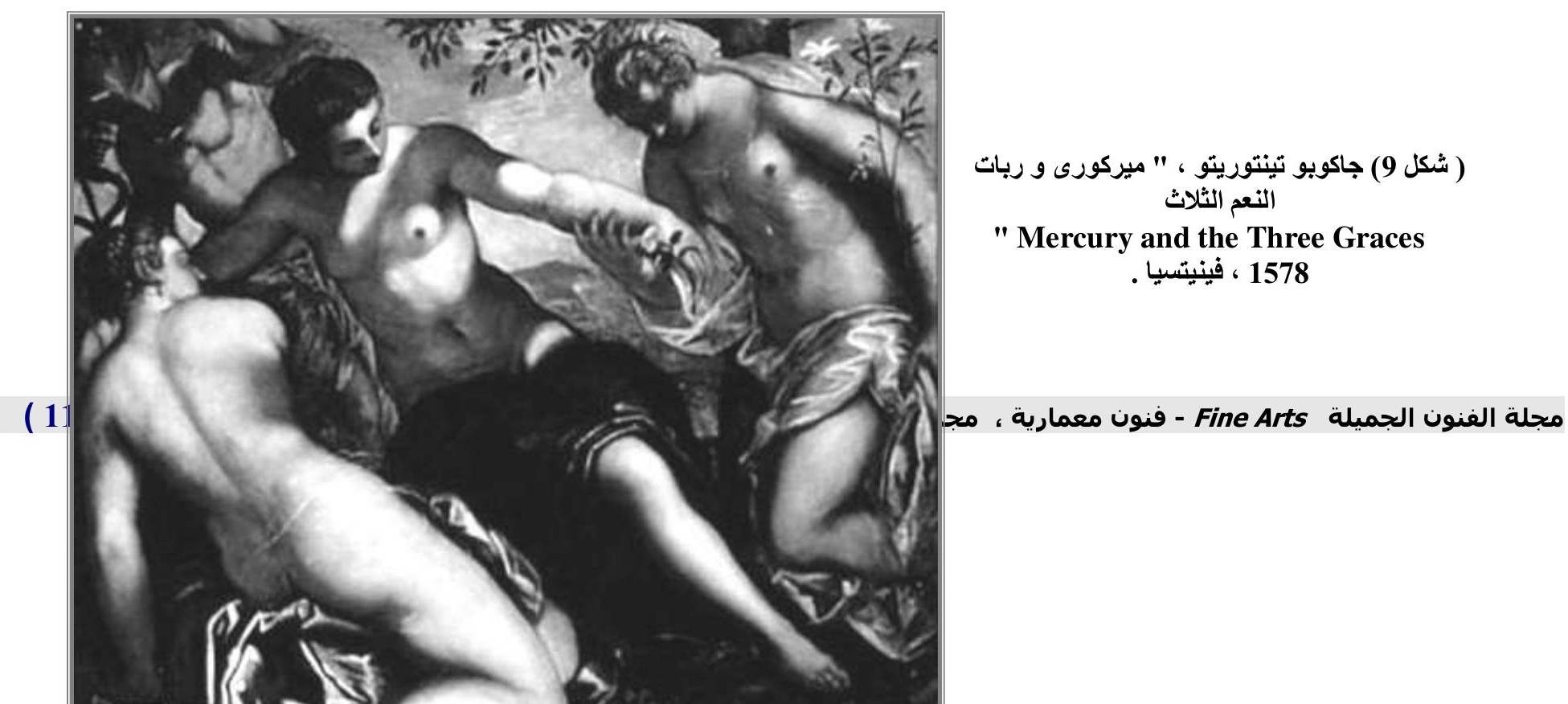




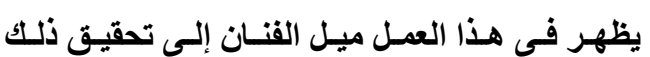

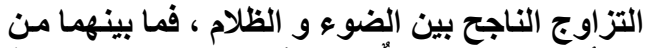
تباينّ و تناغم ، مسلطُ على الأجسام ، ليظهر الحركة

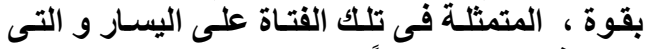

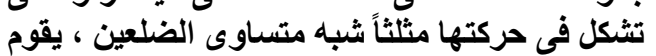

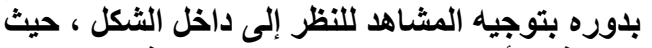

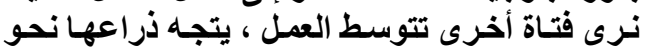
الفتاة الثالثة ، و بذلك التكوين المحكم إستطاع الفتـان ترتيب مدخل العمل الفنى من اليسار إلى اليمين بذكاء

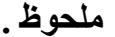

: Peter Paul Rubens بيتز بول روبنز

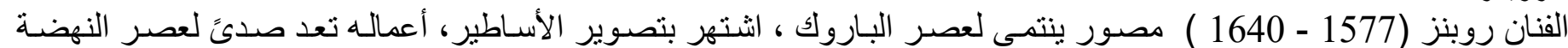

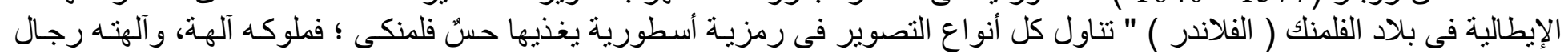

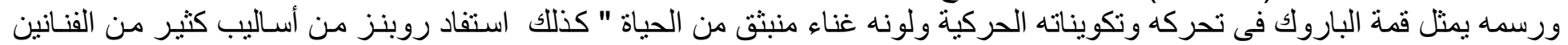

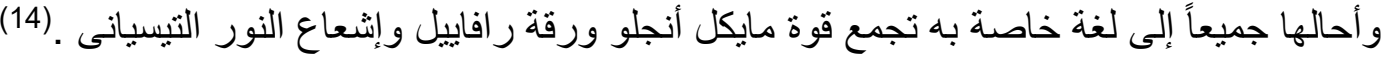

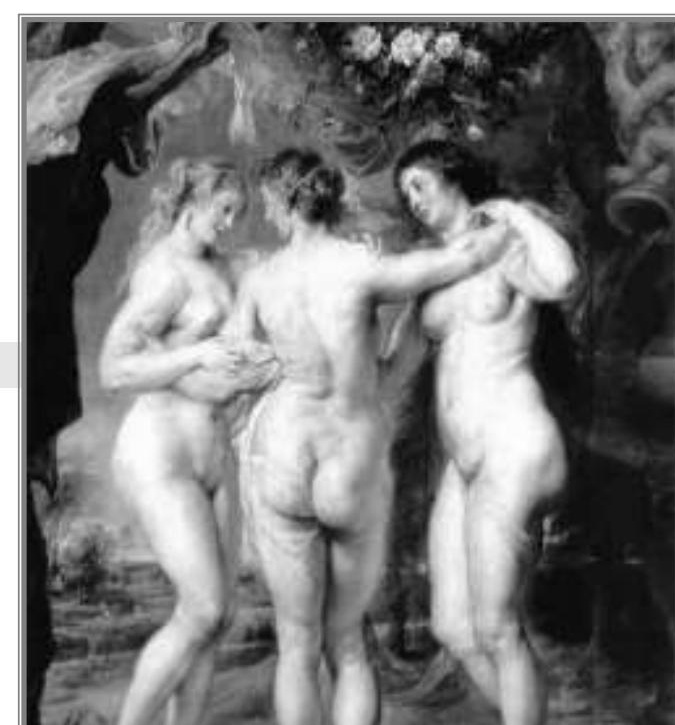

(شكل 10) بيتر بول روينز ، 1621- 1625" .

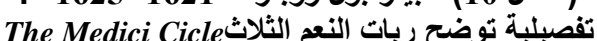

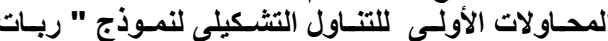

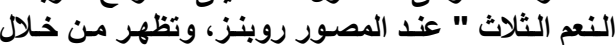
تفيلية لإحدى أعمالة.

عمارية ، محلة ربع سنوية تصدر عن كلية الفنور

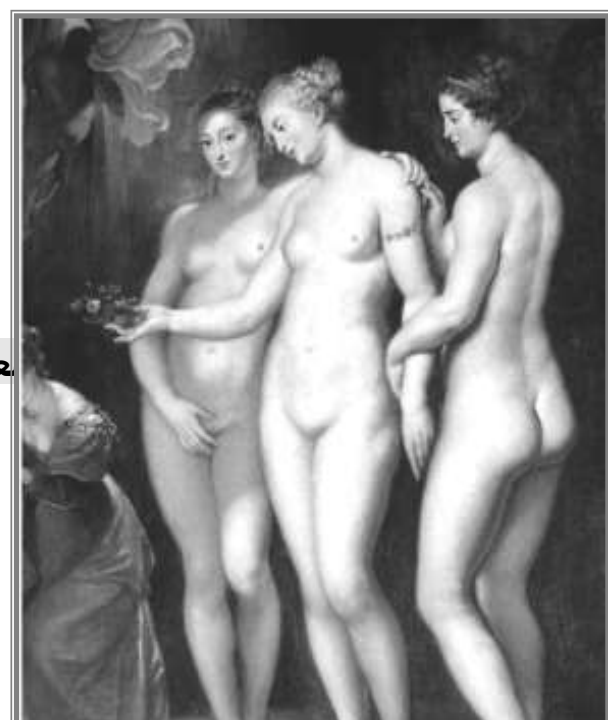




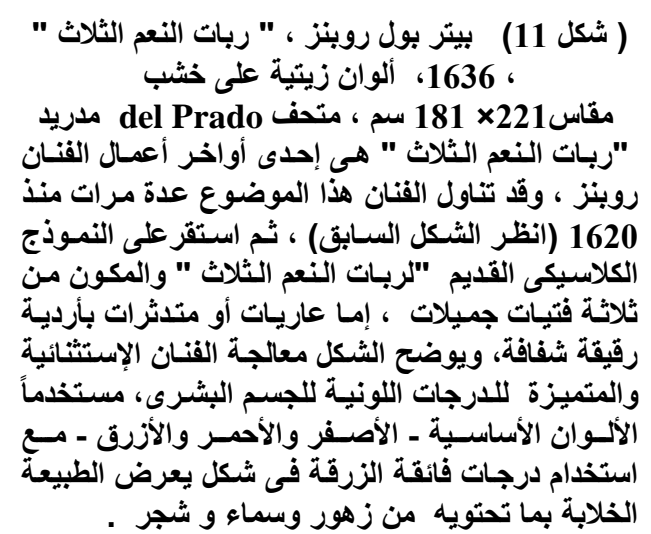

جاك بلانشارد : Jacques Blanchard

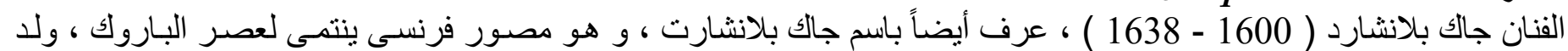

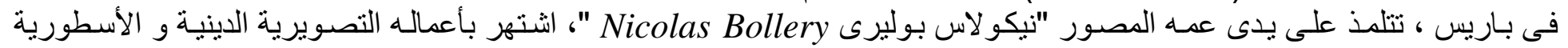

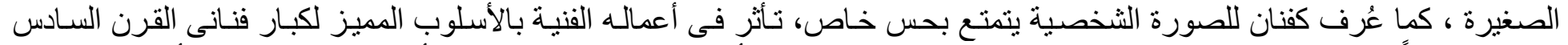

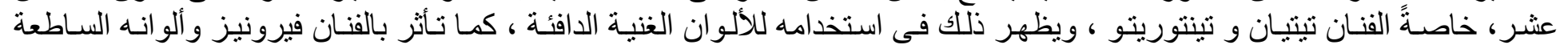

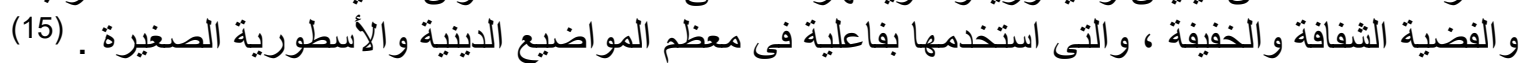

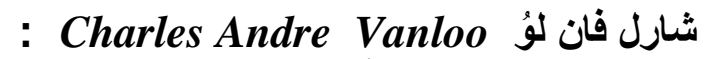

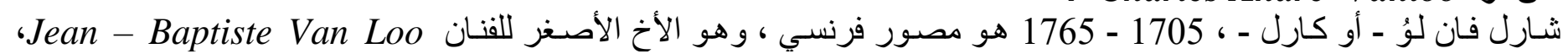

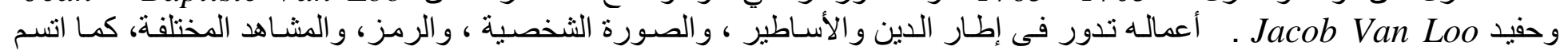

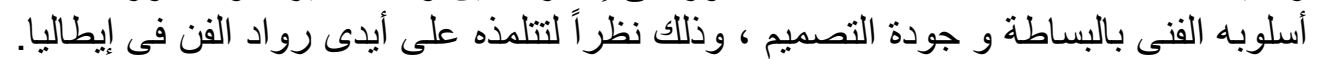




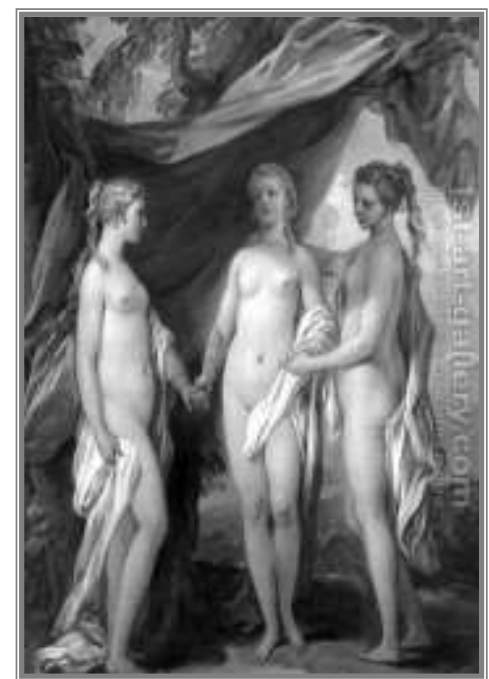

(شكل12) جاك بلانشارد ، فينوس والنعم الثلاث وقد فاجئهن شخصٌ يرمز للموت،

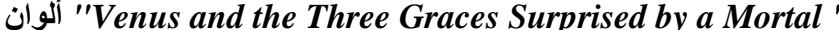

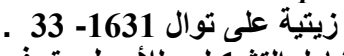

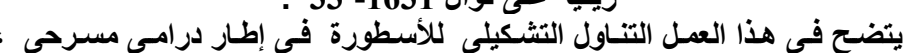

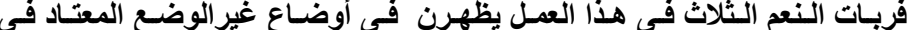

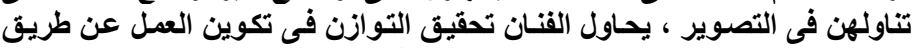

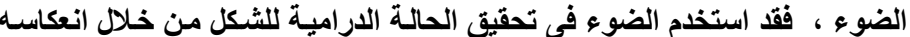

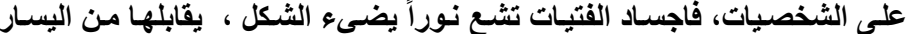

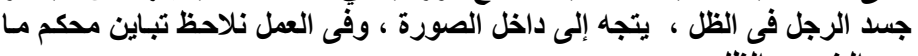

"The Three Graces شكل 13) شارل فان لوُ ربات النعم الثلاث

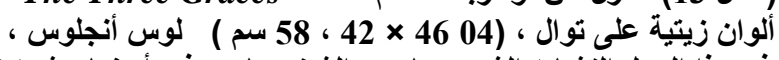

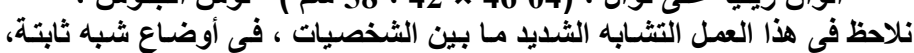

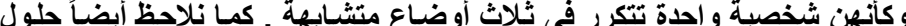

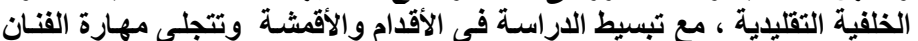

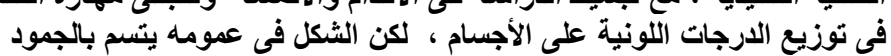

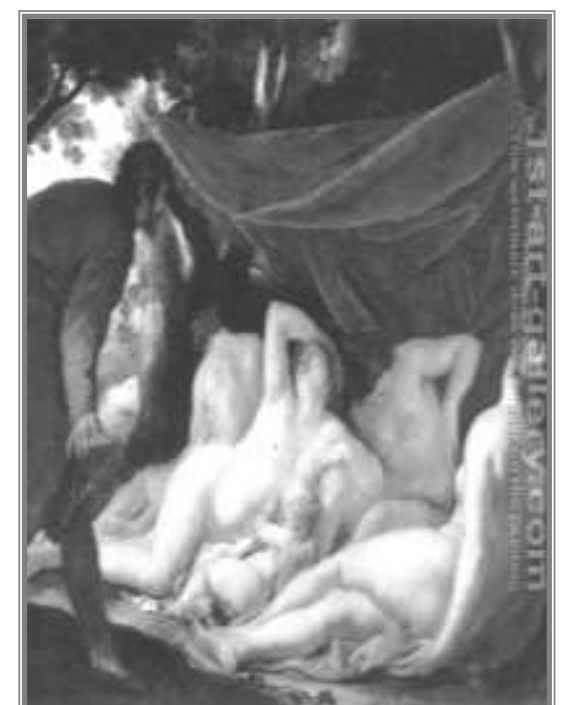

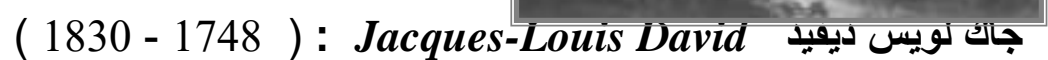

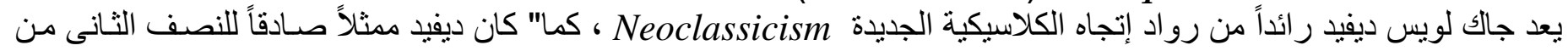

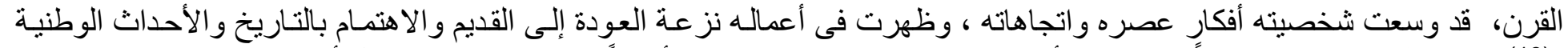

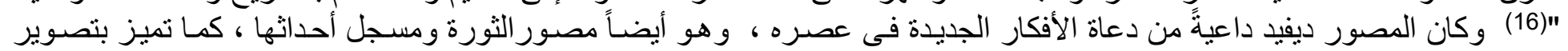

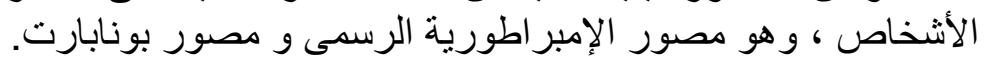

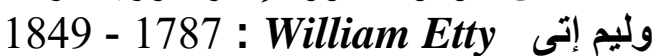

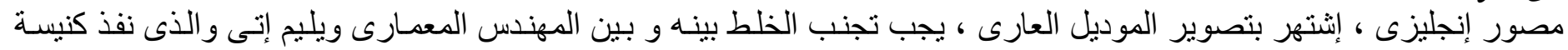

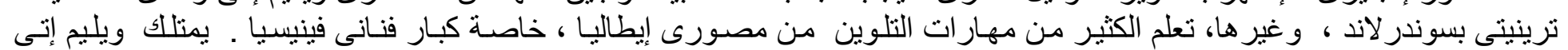

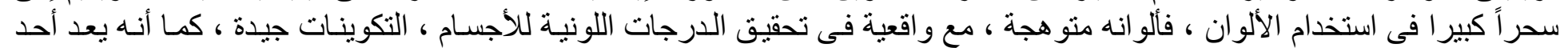

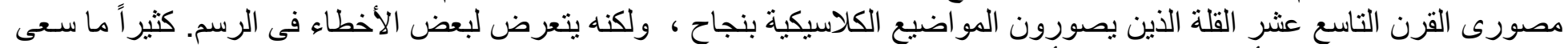

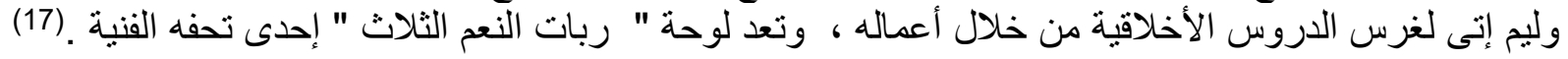
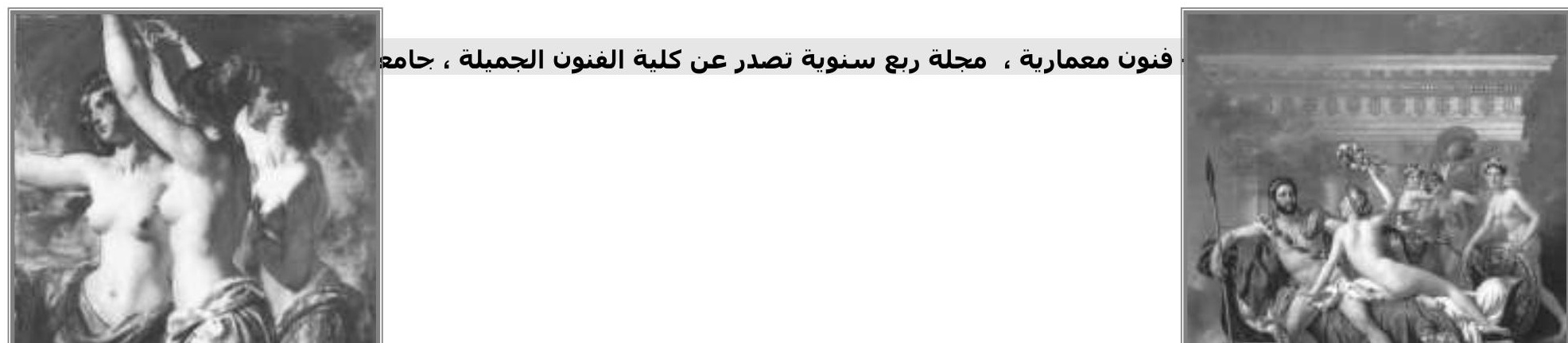
(شكل 14) جاك لويس ديفيد ، " نزع سلاح الإله مارس بواسطة فينوس و ربات

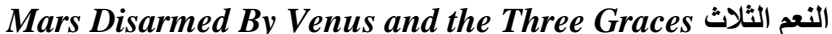

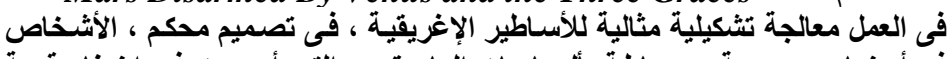

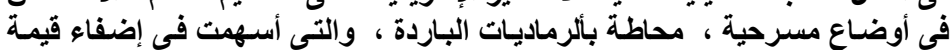

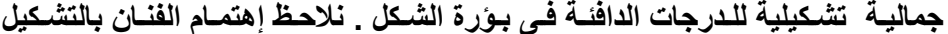

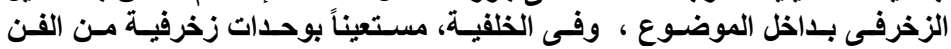

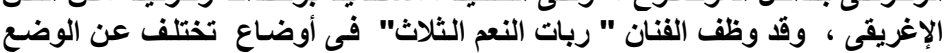

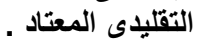

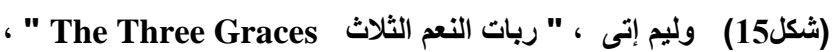

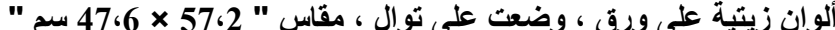

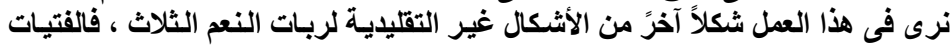

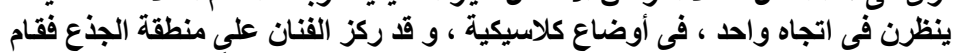

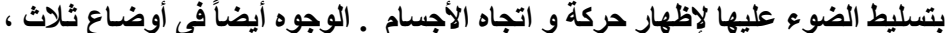

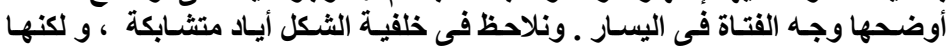

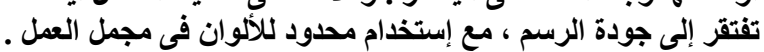

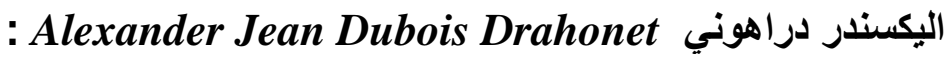

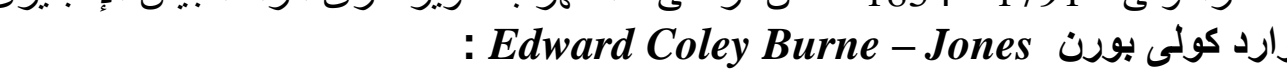

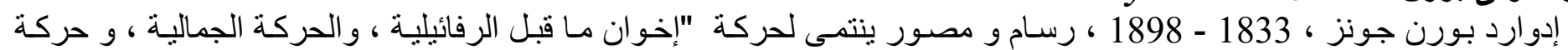

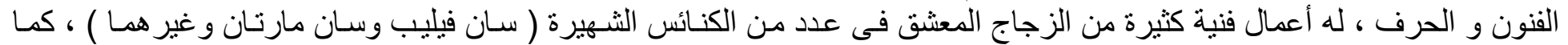

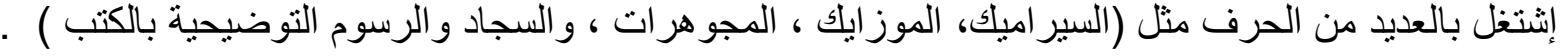

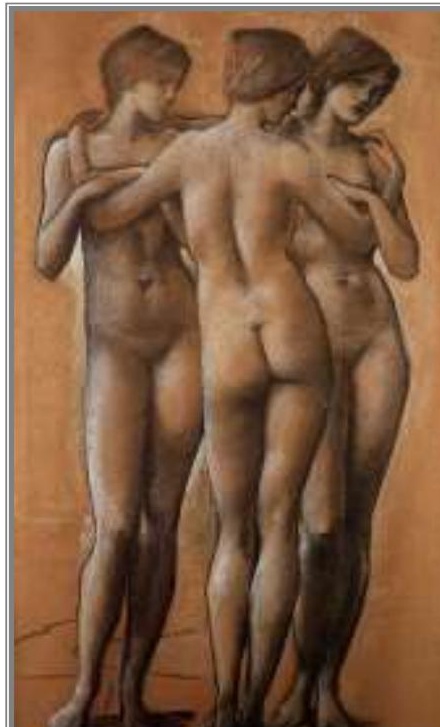

(شكل 16) جان دوبوا دراهونى ، " ربات النعم الثلاث The Three Graces

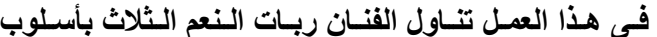

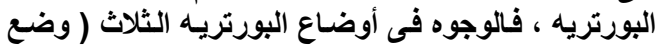

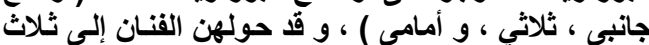

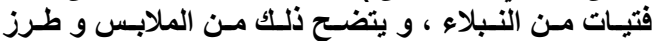
بع سنوية تصدر عن كلية الفنون الجميلة ، جحامعة

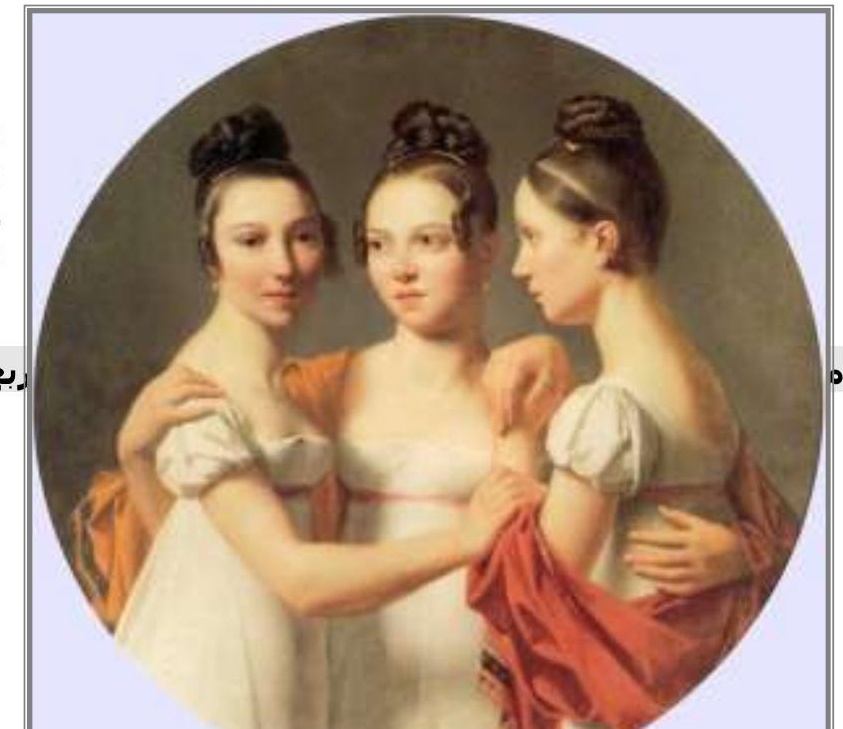


تصفيف الثعرو التى تمثل العصر الذى نفذ فيه ذلك العمل .

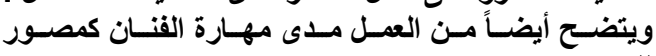
للبورتزيه .
(شكل 17) إوارد كولي بورن ، " ريات النعم الثلاث " ،

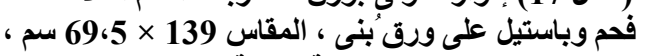

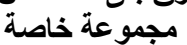

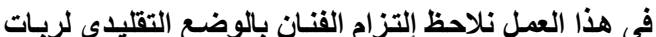

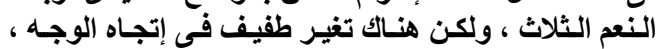

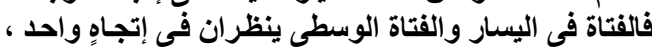

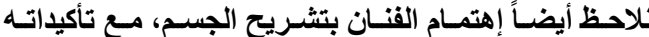
بالباستيل الأبيض لإبراز العضلات، وإتقانهـ لدرجات التظليل بحساسية خاصية الابض لإنرا

جورج فريدريك واتز George Frederick Watts جزئ

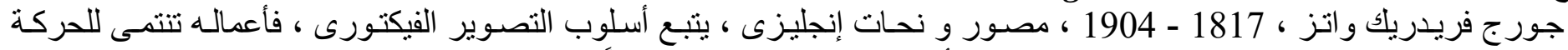

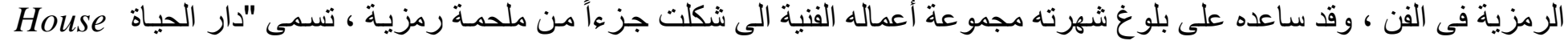
روبرئ و of Life

\section{: Robert Delauny روبيرت ديلونى}

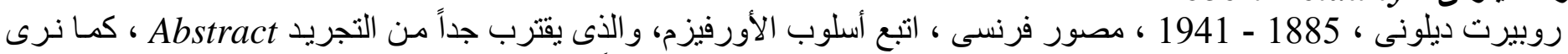
فى أعماله التكعيية، لكنه يركز على الأورفيزم ، أما أعماله المتأخرة فكانت أكثرتجريداً .
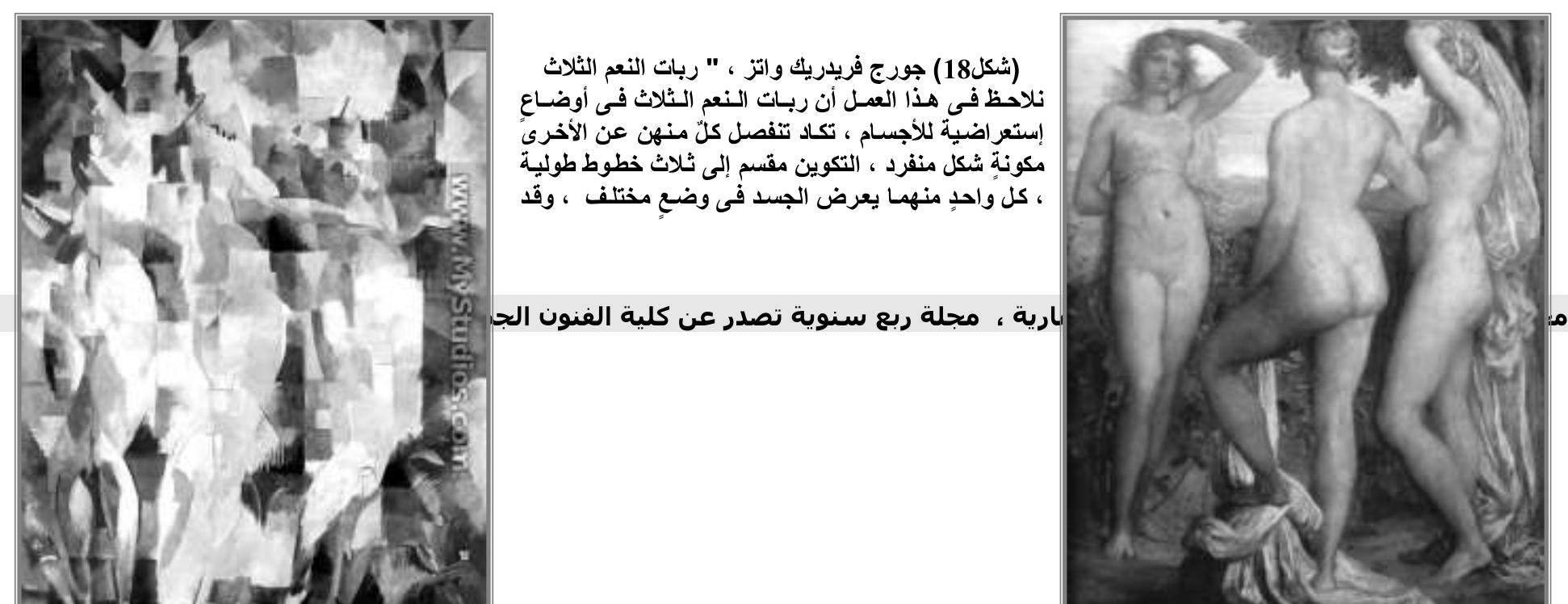


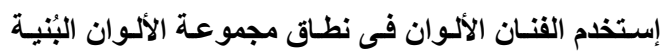
بدرجاتها ، وبحساسية بالغة .

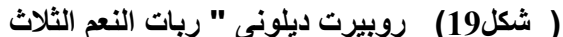

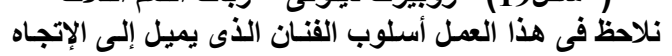

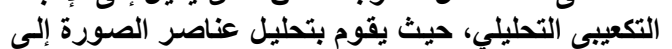

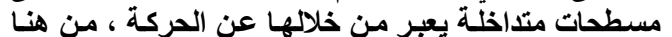

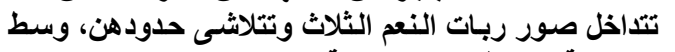

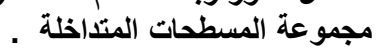

جارى كايمر Gary Kaemmer

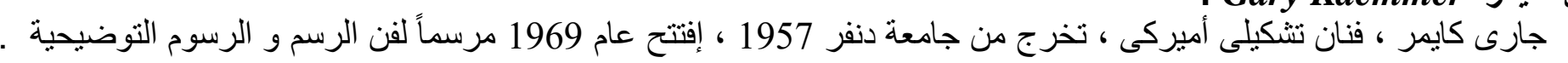

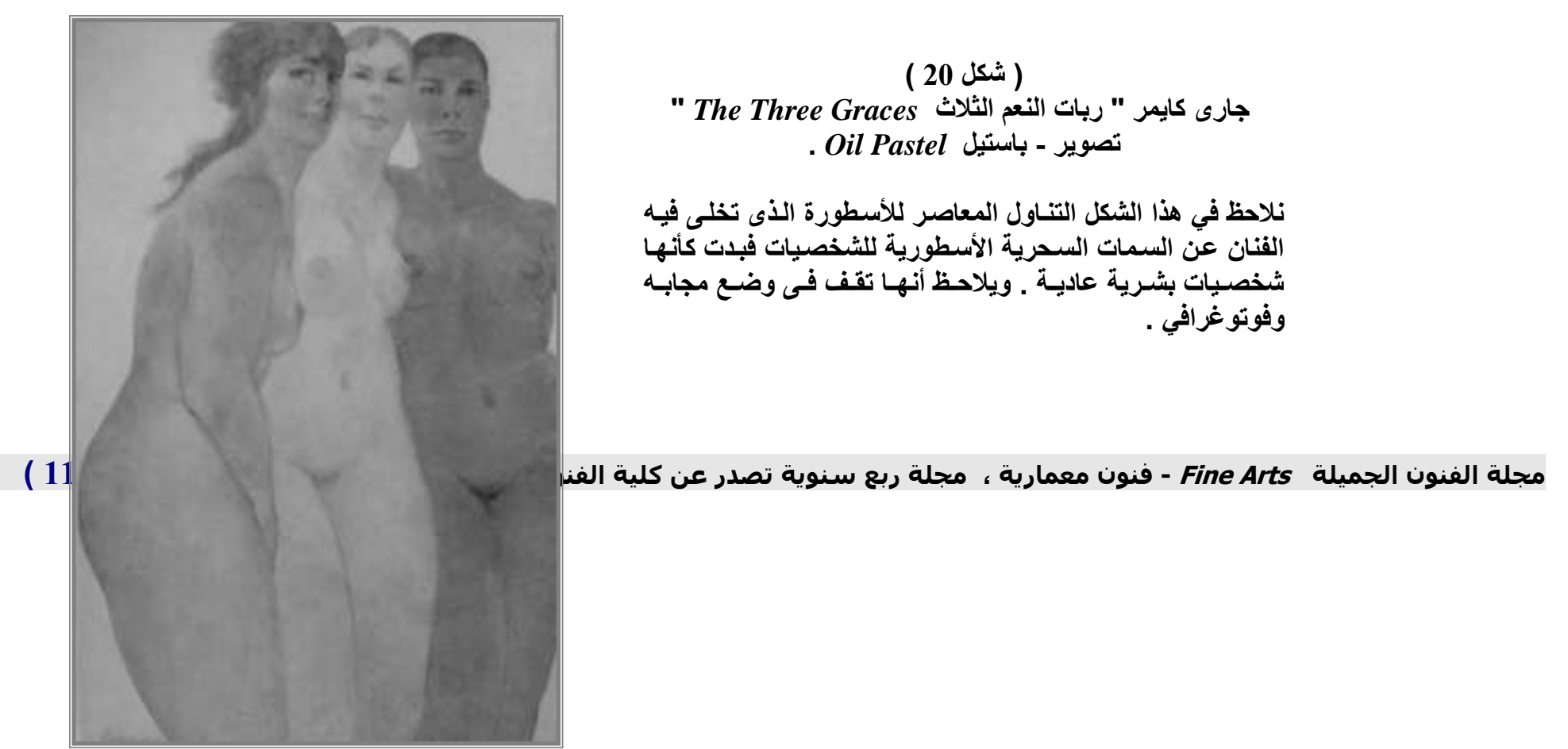




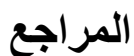

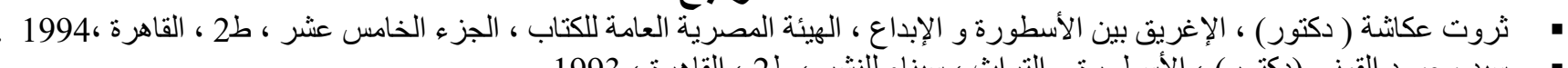

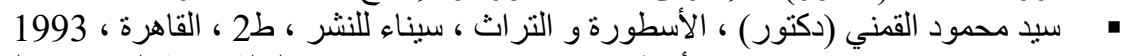

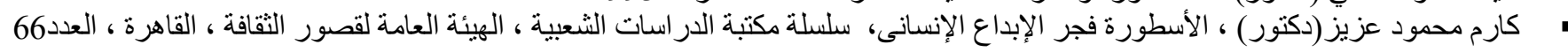

- http://www.paintingall.com

- http://www.metmuseum.org

- http://www.backtoclassics.com

- http://www.mlahanas.de/Greek/Mythology

- .http://www.artchive.com.eg

- http://www.image.google.com.eg

- http://www.hei-art.com

- http://www.threegracesgallery.com

- http://www.paintinghere.com

- http://www.jstor.org

- http://www.globalgallery.com

- http://www.fineartamerica.com

- http://www.marefa.org

- http://www.google.com.eg

- http://www.collectionsonline.iacma.org

- http://www.mystudios.com

- http://www.chinafineart.com

- http://www.jacopotintoretto.org

- http://www.en.wikipedia.org/wiki/Three_Graces

- http://www.jssgallery.org

- http://www.towerweb.net

- http://www.theoi.com

- http://www.1st-art-gallery.com

- http://www.en.wikipedia.org/Edward/Burne/Jones

- http://www.davidoilpainting.com

- http://www.annabaa.org 
- http://www.allartpainting.com

- http://www.artcyclopedia.com

- http://www.huntfor.com
- http://www.framoo.com

- http://www.en.wikipedia.org/Lucas/The/Elder

- http://www.lessing.photo.com 
